\title{
Time Required to Rectify Inhaler Errors Among Experienced Subjects With Faulty Technique
}

\author{
Andrea S Melani MD, Marco Bonavia MD, Eliuccia Mastropasqua MD, Alessandro Zanforlin MD, \\ Marco Lodi MD, Paola Martucci MD, Nicola Scichilone MD, Maria Aliani MD, \\ Margherita Neri MD, and Piersante Sestini MD; on behalf of the Gruppo Educazionale \\ Associazione Italiana Pneumologi Ospedalieri (AIPO)
}

\begin{abstract}
BACKGROUND: Regardless of the device used, many patients have difficulty maintaining proper inhaler technique over time. Repeated education from caregivers is required to ensure persistence of correct inhaler technique, but no information is available to evaluate the time required to rectify inhaler errors in experienced users with a baseline faulty technique and whether this time of re-education to restore inhaler mastery can differ between devices. METHODS: This was a multicenter, single-visit, open-label, cross-sectional study in a large group of 981 adult subjects (mean \pm SD age $64 \pm 15$ y) experienced with inhaler use, mainly suffering from COPD and asthma, who showed faulty inhaler technique at a follow-up visit in chest clinics. These subjects received face-to-face practical education from trained caregivers until proper inhaler use could be demonstrated, and the time of instruction was recorded. RESULTS: The mean times $(95 \%$ CIs) in minutes of instruction required for rectifying misuse and demonstrating inhaler mastery were $5.0(3.6-6.4) \mathrm{min}$ for the Diskus $(n=199), 5.3(3.7-6.8) \mathrm{min}$ for the HandiHaler $(n=219), 8.1(5.6-10.5) \mathrm{min}$ for the metered-dose inhaler (MDI) $(n=532)$, and 6.0 (5.0-7.0) $\mathrm{min}$ for the Turbuhaler $(n=169)$. The time to demonstrate good inhaler use for MDIs was higher $(P<.05)$ than for all dry powder inhalers (DPIs). Between the DPIs, only the HandiHaler required more time for achieving mastery than the Diskus $(P=.005)$. The variables associated with increasing time for correcting inhaler errors were an older age $(0.05 \mathrm{~min} / \mathrm{y}, 95 \%$ CI $0.03-0.07)$, a lower level of education $(0.4 \mathrm{~min} /$ schooling level, 95\% CI 0.7-0.1), and no reported previous instruction in inhaler use (1.96 min, 95\% CI 1.35-2.58). CONCLUSIONS: In experienced subjects with baseline faulty inhaler use, the mean time of education required to achieve and demonstrate mastery with DPIs was lower than with MDIs. Key words: asthma; COPD; inhaler device. [Respir Care 2017;62(4):409-414. (C) 2017 Daedalus Enterprises]
\end{abstract}

\section{Introduction}

Inhalation is the preferred route of drug administration for treating chronic obstructive airway diseases, such as

Dr Melani is affiliated with Fisiopatologia e Riabilitazione Respiratoria, Policlinico Le Scotte, Azienda Ospedaliera Universitaria Senese, Siena, Italy. Dr Bonavia is affiliated with Pneumologia, Ospedale La Colletta, Arenzano, Italy. Dr Mastropasqua is affiliated with Fisiopatologia Respiratoria, IRCCS Regina Elena, Rome, Italy. Dr Zanforlin is affiliated with SOC Medicina, Ospedale S. Luca, Trecenta, Italy. Dr Lodi is affiliated with Malattie Apparato Respiratorio, Ospedale di Copparo, Ferrara, Italy. Dr Martucci is affiliated with Centro anti-fumo, Ospedale Cardarelli, Naples, Italy. Dr Scichilone Dipartimento Medicina, Pneumologia, Fi- asthma and COPD. Delivery of medication to the lungs requires specific devices. The most commonly used inhalers are metered-dose inhalers (MDIs) and dry powder inhalers (DPIs). Within these groups, manufacturers have developed a range of devices with different handling. All marketed devices are equally effective, even if sometimes

\footnotetext{
siologia e Nutrizione Umana, Università di Palermo, Palermo, Italy. Dr Aliani is affiliated with the Divisione di Pneumologia, ICCRS Fondazione Maugeri, Cassano delle Murge, Italy. Dr Neri is affiliated with the Istituto Fondazione Renato Piatti, Varese, Italy. Dr Sestini is affiliated with the Clinica Malattie Apparato Respiratorio, Università di Siena, Siena, Italy.
} 
at different dosages, when inhalation is performed correctly. ${ }^{1}$ Unfortunately, poor inhaler technique with MDIs and DPIs is common in real life. ${ }^{2}$ The burden of inhaler errors is huge, since it may worsen clinical outcomes ${ }^{2}$ and has been estimated to waste 5-7 billion dollars every year. ${ }^{3}$ Misuse is common not only in naive, but even in experienced users. Approximately half of patients have subsequent difficulty in maintaining inhaler mastery irrespective of the device used and the duration of follow-up..$^{4-7}$ As a consequence, the role of education from trained caregivers is important to reduce poor inhaler technique not only at the time of the first prescription but also at follow-up visits. ${ }^{8,9}$ Many studies have evaluated the time required for educating naive adult users to inhaler mastery, ${ }^{10-17}$ but, to our knowledge, no information is available to evaluate the re-education time required to achieve inhaler mastery in experienced users with faulty baseline technique. Our previous study, the GENEBI Project ${ }^{2}$, investigated home inhaler practice among experienced stable subjects with chronic obstructive airway diseases referred to chest clinics throughout Italy. A subset of these subjects performed inhaler errors at baseline. Then subjects with faulty technique received education until inhaler mastery was achieved. The time of re-education required to rectify inhaler errors was measured. These results constitute the aim of the present study.

\section{Methods}

Details of the materials and the methods of the GENEBI Project have already been published. ${ }^{2}$ Briefly, during the study period, all adolescent and adult patients (age $>14 \mathrm{y}$ ), attending one of the participating centers for an ambulatory scheduled visit and regularly using an inhaler at home, were considered eligible for participation. The enrollment always occurred after a full explanation of the study and written informed consent. The study was conducted in accordance with the Declaration of Helsinki and Good Clinical Practice guidelines and approved by the ethics committee of the participating centers. Enrolled subjects were asked to demonstrate the use of their inhalers to the investigator in a quiet area with a placebo device using the same modalities that they utilized at home. Observations

The authors have disclosed no conflicts of interest.

Supplementary material related to this paper is available at http:// www.rcjournal.com.

Correspondence: Andrea S Melani MD, Fisiopatologia Respiratoria, Policlinico Le Scotte Viale Bracci, I-53100 Siena, Italy. E-mail: a.melani@ao-siena.toscana.it.

DOI: $10.4187 /$ respcare. 05117

\section{QUICK LOOK}

\section{Current knowledge}

Regardless of the device used, many subjects have difficulty maintaining proper inhaler technique over time. Repeated education is required to ensure the persistence of good inhaler use, but it is unknown whether the time required to rectify inhaler errors between devices differs.

\section{What this paper contributes to our knowledge}

In a large group of subjects with chronic obstructive airway disease who were experienced in using inhaled treatment, we found baseline faulty inhaler use. The mean time of education from trained caregivers required to rectify inhaler misuse with dry powder inhalers was lower than with metered-dose inhalers.

were reported in accordance to a standardized predefined checklist, including a variable number of steps for each inhaler. For each center, a single trained investigator recorded the modalities of inhaler use; to standardize their findings, periodic meetings were held with all of the participating observers. Published results focused on critical errors, which are likely to make inhaled therapy useless. ${ }^{2}$ Then subjects who performed at least one error were instructed until they were able to demonstrate full mastery (teaching to goal) with the inhaler(s) erroneously utilized at baseline. Errors were evaluated in accordance with the standardized checklist reported in supplementary Table 1 (see the supplementary materials at http://www.rcjournal. com). We recorded the time from the start of the teaching session until the end of the first demonstration of proper inhaler use (ie, all steps were correct). If a subject was using more devices and performed errors with all these inhalers, we independently evaluated and recorded the time of re-education for all devices with faulty technique. As part of ethics, the participants who did not succeed in achieving adequate inhaler technique according to the investigator's judgment were switched to other devices and received counseling until they could use their inhalers effectively.

Baseline data were analyzed and reported for the subset of subjects performing at least one inhaler error. Descriptive statistics were used to summarize the subjects' demographic and clinical characteristics. Unless reported otherwise, results are stated as percentages, means, SE, and $95 \%$ CI. $P<.05$ was considered significant. All analyses were performed with a multilevel mixed effect linear regression using subjects and centers as random effect variables and other confounders as fixed effect variables (Stata 12 for Windows, Stata Corp, College Station, Texas). 


\section{Correcting Inhaler Technique in Experienced SubJects}

Table 1. Clinical and Demographic Characteristics of Study Participants Performing at Least One Error in Inhaler Technique but Able to Achieve Proper Inhaler Mastery After Instruction

\begin{tabular}{|c|c|c|c|c|c|c|}
\hline Device & $n(\%)^{*}$ & Males, \% & $\begin{array}{c}\text { Mean } \\
\text { Age } \pm \text { SD, y }\end{array}$ & $\begin{array}{c}\text { Mean } \mathrm{FEV}_{1} \pm \mathrm{SD} \\
\% \text { Predicted }\end{array}$ & $\begin{array}{l}\text { Subjects with } \\
\text { Asthma, } \%\end{array}$ & $\begin{array}{c}\mathrm{S}_{\mathrm{pO}_{2}}<90 \% \text { at } \\
\text { Rest While } \\
\text { Breathing Air, } n\end{array}$ \\
\hline Aerolizer & $27(33)$ & 63 & $60 \pm 16$ & $61 \pm 24$ & 60 & 3 \\
\hline Diskus & 199 (43) & 61 & $67 \pm 12$ & $67 \pm 20$ & 30 & 6 \\
\hline HandiHaler & $219(43)$ & 63 & $73 \pm 9$ & $60 \pm 19$ & 9 & 7 \\
\hline MDI & $532(63)$ & 55 & $60 \pm 17$ & $67 \pm 25$ & 52 & 11 \\
\hline Turbohaler & 169 (47) & 60 & $63 \pm 17$ & $69 \pm 21$ & 49 & 4 \\
\hline
\end{tabular}

\section{Results}

This study included 981 subjects with a baseline faulty inhaler technique with at least one device. They mainly suffered from COPD (64\%) and asthma (33\%). Their mean age \pm SD was $64 \pm 15 \mathrm{y}$, and $61 \%$ were males. Some demographic and clinical characteristics of subjects with at least one overall error have been reported in Table 1.

Almost $40 \%$ of subjects were using more than one type of inhaler simultaneously; of these, 176 subjects performed errors with 2 inhalers, and 13 subjects performed errors with 3 devices. Overall, we obtained 1,282 observations of inhalation technique with at least one error at the baseline performance. For the aim of the present study, we restricted the analysis to devices with a minimal sample size of 20 observations, selecting the 5 inhalers that were the most commonly used devices in the study period in Italy.

In accordance with the investigator's judgment of persistent difficulty in achieving a good inhaler technique despite extensive instruction, a switch to another device was agreed upon with the 27 subjects $(2.1 \%)$. The switch pertained to subjects using the Diskus (Accuhaler, GSK, Brentford, Middlesex, UK) $(n=3)$, HandiHaler (Boeringer Ingelheim, Ingelheim, Germany) $(n=8)$, MDI $(n=13)$, and Turbuhaler (AstraZeneca, Lund, Sweden) $(n=6)$ at baseline. The specific errors leading to the change and the nature of the switch were not recorded.

The mean time $(95 \% \mathrm{CI})$ in minutes required for achieving and demonstrating proper inhaler technique is reported in Table 2. We did not find any difference in the time required for rectifying misuse in subjects performing errors with 2 or more inhalers versus those with one device.

The role of some variables influencing the time to correct inhaler errors is reported in Table 3 . When we performed a multivariate analysis after adjustment for age, level of education, and diagnosis of asthma for both overall and critical errors, the time required to achieve and demonstrate proper inhaler technique with MDIs was higher than with all DPIs, as shown in Tables 4 and 5.
Table 2. Mean Time Required for Demonstrating Inhaler Mastery in Subjects With at Least One Inhaler Error at the Baseline Performance

\begin{tabular}{llc}
\hline \hline \multirow{2}{*}{ Device } & \multicolumn{2}{c}{ Mean Time $\begin{array}{c}\text { (95\% CI) for Correcting } \\
\text { Errors, min }\end{array}$} \\
\cline { 2 - 3 } & \multicolumn{1}{c}{ All Errors } & Critical Errors \\
\hline Aerolizer & $7.9(3.1-12.7)$ & $7.3(1.3-13.2)$ \\
Diskus & $5.0(3.6-6.4)$ & $5.1(3.5-6.7)$ \\
HandiHaler & $5.3(3.7-6.8)$ & $5.3(3.6-7.0)$ \\
MDI & $8.1(5.6-10.5)$ & $12.2(8.3-16.0)$ \\
Turbuhaler & $6.0(5.0-7.0)$ & $6.0(5.0-7.0)$ \\
\hline
\end{tabular}

Table 3. Variables Affecting Learning Time for Correcting Inhaler Misuse

\begin{tabular}{|c|c|}
\hline Variable & Level of Significance \\
\hline Increasing age & $0.05 \mathrm{~min} / \mathrm{y} ; 95 \%$ CI $0.03-0.07 ; P<.001$ \\
\hline Lower level of instruction & $\begin{array}{l}0.4 \mathrm{~min} / \mathrm{schooling} \text { level } * ; 95 \% \text { CI } 0.7-0.1 ; \\
\quad P=.007\end{array}$ \\
\hline $\begin{array}{l}\text { No previous instruction of } \\
\text { inhaler use }\end{array}$ & $1.96 \mathrm{~min} ; 95 \%$ CI $1.35-2.58 ; P<.001$ \\
\hline Sex & $0.11 \mathrm{~min} ; 95 \% \mathrm{CI}-0.39$ to $0.62 ; P=.66$ \\
\hline $\begin{array}{l}\text { Hemoglobin oxygen } \\
\text { saturation levels at } \\
\text { rest while breathing air } \\
\left(\mathrm{S}_{\mathrm{pO}_{2}}<90 \%\right)\end{array}$ & $0.37 \mathrm{~min} ; 95 \%$ CI $0.39-1.33 ; P=.29$ \\
\hline
\end{tabular}

When we compared DPIs with each other, adjusting for the same variables, only the HandiHaler required slightly more time for correcting inhaler errors than the Diskus, as shown in Table 6.

\section{Discussion}

The main strengths of our study are the large number of participants, the inclusion of several centers with the same 
Table 4. Difference of Time in Minutes Required for Correcting Overall Errors Between Metered-Dose Inhalers and Other Devices

\begin{tabular}{lccc}
\hline \hline \multicolumn{1}{c}{ Device } & Mean Difference & $95 \%$ CI & $P$ \\
\hline Turbuhaler & -0.9 & -1.6 to -0.2 & .01 \\
Diskus & -1.4 & -2.1 to -0.8 & .001 \\
HandiHaler & -0.6 & -1.3 to -0.01 & .047 \\
Aerolizer & -3.5 & -5.1 to -1.9 & $<.001$ \\
\hline
\end{tabular}

Table 5. Difference of Time Required for Correcting Critical Errors Between Metered-Dose Inhalers and Other Devices

\begin{tabular}{lcc}
\hline \hline \multicolumn{1}{c}{ Device } & Mean Difference, ${ }^{*} \min$ & $95 \%$ CI \\
\hline Turbuhaler & -3.6 & -4.7 to -2.6 \\
Diskus & -4.1 & -5.1 to -3.1 \\
HandiHaler & -3.2 & -4.2 to -2.3 \\
Aerolizer & -4.5 & -6.5 to -2.5
\end{tabular}

* All differences were at the level of $P<001$.

Table 6. Difference of Time in Minutes for Correcting Critical Inhaler Errors Between HandiHaler and Other Dry Powder Inhalers

\begin{tabular}{lccc}
\hline \hline \multicolumn{1}{c}{ Device } & Difference & \multicolumn{1}{c}{$95 \%$ CI } & $P$ \\
\hline Turbuhaler & -0.40 & -1.15 to 0.35 & .29 \\
Diskus & -0.86 & -1.47 to -0.26 & .005 \\
Aerolizer & -1.27 & -3.31 to 0.77 & .22 \\
\hline
\end{tabular}

standardized method of investigation, and the lack of any sponsorship from manufacturers.

This study has some weaknesses. First, it was an observational study where assessment was only based on the investigators' judgment, although every effort was made to standardize the observations of inhaler technique and errors were defined in accordance to a predefined checklist for all studied devices. Second, although our checklists were based on literature data and manufacturer leaflets, we recognize that, to date, there is no full agreement in what is considered as either an overall error or a critical error. Third, the type of education may largely influence the time required for rectifying inhaler misuse. However, of all of the possible training approaches, a face-to-face practical demonstration using inhaler placebos until a proper inhaler mastery was achieved is estimated to be the most effective method of instruction in real life. ${ }^{7,8,18-20}$ In our study, the provision of feedback on how to correct errors was only qualitative. It has been found that a quantitative approach may offer better results. ${ }^{21}$ All investigators were chest physicians, but we think that the expertise of the instructor more than the role has relevance. However, prior the study all investigators discussed and achieved consensus on inhalation technique of all studied devices. ${ }^{19}$ The study population may also influence the average time of instructions for achieving inhaler mastery. Our study only included stable adult subjects mainly with asthma and COPD. In other settings, such as in the emergency room or in hospitalized subjects, results might be different.

The primary finding of this study is that most experienced subjects with faulty baseline technique could achieve inhaler mastery after proper education. This finding is not unexpected, because the prescribing physicians could have already geared the choice of the device toward the best inhaler in terms of usability. In the present study, we did not record the specific errors leading to the change and the nature of the switch of devices. Other works could evaluate this interesting point. However, the key finding of the study is that the time to demonstrate inhaler mastery with MDIs was greater than that with DPIs. This was observed when either critical or overall (critical and not critical) errors were considered. Notably, whereas the absolute number of errors with MDIs was higher than that with the other devices, we had previously shown that the rate of critical errors with MDIs was similar to that with DPIs. ${ }^{2}$ Hence, we can conclude that the greater requirement of time for education with MDIs was independent of the number of errors performed at baseline. Many clinicians think that MDIs are more complicated and require more skill to use than DPIs. Our findings add some further objective results to this opinion. We have combined all observations of MDIs into one group; this may not be quite correct, since MDIs can differ in usage: For instance, only some MDIs are formulated as solutions, so they do not require being shaken before use, whereas others are suspensions and must be shaken. Moreover, they can differ in taste, plume duration, temperature, and force. Further studies should investigate this topic.

Among DPIs, the only significant difference in time required to achieve inhaler mastery was between the HandiHaler and the Diskus. These devices have a different number of steps for usage. Although we agree that a comparison between devices with different handling may seem unnecessary, this occurs in real life.

Technological advancements have permitted the introduction of newer devices with fewer steps for usage, even with respect to the Diskus. It will be interesting to evaluate whether this can translate to a lower time of instruction for achieving mastery not only in naive patients, ${ }^{16,20}$ but even in experienced patients unable to maintain a proper inhaler technique over time.

\section{Conclusions}

Because the persistence of a good inhaler technique may decline over time, caregivers will have sufficient time 


\section{Correcting Inhaler Technique in Experienced SubJects}

to monitor inhaler techniques at every follow-up visit and instruct users, when necessary, to maintain inhaler mastery. We have shown that in our setting, the mean time to rectify inhaler misuse with DPIs was lower than with MDIs. This finding may be relevant for the choice of inhaler device.

\section{ACKNOWLEDGMENTS}

We acknowledge all of the members of the Educational Group AIPO for contributions in the collection of data, including Francesco Falcone, past president of AIPO, and Carlo Zerbino, Director of AIPO, for contributions to the realization of the study.

Gruppo Educazionale Associazione Italiana Pneumologi Ospedalieri (AIPO): Study Participants.

UOC Fisiopatologia e Riabilitazione Respiratoria, Azienda Ospedaliera Universitaria Senese, Policlinico Le Scotte, Siena, Italy: Andrea Sisto Melani.

Divisione di Pneumologia, Fondazione S Maugeri, ICCRS Istituto Scientifico di Cassano Murge (Ba), Italy: Maria Aliani.

Divisione di Pneumologia, Ospedale G. da Procida, Salerno, Italy: Natalino Barbato.

UOC Pneumologia, Ospedale La Colletta, Arenzano (Ge), Italy: Marco Bonavia.

Pneumologia-Osp S Bartolomeo, Sarzana (SP), Italy: Piero Aldo Canessa.

Fisiopatologia Respiratoria, IRCCS Regina Elena, Roma, Italy: Vincenzo Cilenti, Eliuccia Masatropasqua.

UO Pneumotisiatria-Ospedale Bellaria, Bologna, Italy: Cristina Cinti, Alessandro Zanforlin: Vincenzo Zagà, Vicenza Mariano.

UOS di Pneumologia Ospedale "C. Magati" AUSL di Reggio Emilia, Scandiano (RE), Italy: Isotta Coloretti.

UOC Riabilitazione Respiratoria, Ospedale Forlanini, Roma, Italy: Giuseppe DeAngelis.

UO Pneumologia, AO G Rummo-Benevento, Italy: Mario DelDonno. UO Pneumotisiologia territoriale, Putignano (Bari), Italy: Renato DeTullio.

UOC Endoscopia toracica e Urgenze Broncologiche-AO A Cardarelli, Napoli, Italy: Raffaela Giacobbe.

UO Malattie Apparato Respiratorio-Copparo, AUSL Ferrara, Italy: Marco Lodi.

Centro antifumo, AO A Cardarelli Napoli, Italy: Paola Martucci.

Divisione di Pneumologia, Fondazione S Maugeri, ICCRS Istituto

Scientifico di Tradate (Va), Italy: Margherita Neri, Sabrina della Patrona.

SC Pneumologia, Ospedale S.Croce e Carle, Cuneo, Italy: Maria Stella Delfino, Paolo Noceti.

UO Pneumologia, Ospedale Mariano Santo, Cosenza, Italy: Ines Scarlato, Francesco Romano.

Dip. Medicina, Pneumologia, Fisiologia e Nutrizione Umana, Università di Palermo, Italy: Nicola Scichilone.

UO Pneumologia -Stab. Osped. Imperia; Maria Serra.

UO Pneumologia, Ospedale Villa Scassi-Genova, Italy: Antonella Serafini.

UOC Pneumologia, ACO S.Filippo Neri Roma, Italy: Albino Sini.

UOC Pneumologia, Ospedale Salvini, Garbagnate (Mi), Italy: Adriano Vaghi.

Laboratorio di Fisiopatologia Respiratoria, Ospedale Sauk, Tirana, Albania: Ylli Vakefflliu.

Area Territoriale Tisio-Pneumologica, Vicenza, Italy: Doriana Zanchetta.

\section{REFERENCES}

1. Dolovich MB, Ahrens RC, Hess DR, Anderson P, Dhand R, Rau JL, et al. Device selection and outcomes of aerosol therapy: evidencebased guidelines. Chest 2005;127(1):335-371.

2. Melani AS, Bonavia M, Cilenti V, Cinti C, Lodi M, Martucci P, et al. Inhaler mishandling remains common in real life and is associated with reduced disease control. Respir Med 2011;105(6):930-938.

3. Fink JB, Rubin BK. Problems with inhaler use: a call for improved clinician and patient education. Respir Care 2005;50(10):1360-1374; discussion 1374-1375.

4. Westerik JA, Carter V, Chrystyn H, Burden A, Thompson SL, Ryan $\mathrm{D}$, et al. Characteristics of patients making serious inhaler errors with a dry powder inhaler and association with asthma-related events in a primary care setting. J Asthma 2016;53(3):321-329.

5. Basheti IA, Reddel HK, Armour CL, Bosnic-Anticevich SZ. Counseling about turbuhaler technique: needs assessment and effective strategies for community pharmacists. Respir Care 2005;50(5):617623.

6. Basheti IA, Armour CL, Bosnic-Anticevich SZ, Reddel HK. Evaluation of a novel educational strategy, including inhaler-based reminder labels, to improve asthma inhaler technique. Patient Educ Couns 2008;72(1):26-33.

7. Bosnic-Anticevich SZ, Sinha H, So S, Reddel HK. Metered-dose inhaler technique: the effect of two educational interventions delivered in community pharmacy over time. J Asthma 2010;47(3):251256

8. Sestini P, Cappiello V, Aliani M, Martucci P, Sena A, Vaghi A, et al. on behalf of the Associazione Italiana Pneumologi Ospedalieri (AIPO) Educational Group. Prescription bias and factor associated with improper use of inhalers. J Aerosol Med 2006;19(2):127-136.

9. Laube BL, Janssens HM, de Jongh FH, Devadason SG, Dhand R, Diot $\mathrm{P}$, et al. What the pulmonary specialist should know about the new inhalation therapies. Eur Respir J 2011;37(6):1308-1331.

10. Gray SL, Williams DM, Pulliam CC, Sirgo MA, Bishop AL, Donohue JF. Characteristics predicting incorrect metered-dose inhaler technique in older subjects. Arch Intern Med 1996;156(9):984-988.

11. Jones V, Fernandez C, Diggory P. A comparison of large volume spacer, breath-activated and dry powder inhalers in older people. Age Ageing 1999;28(5):481-484.

12. Lenney J, Innes JA, Crompton GK. Inappropriate inhaler use: assessment of use and patient preference of seven inhalation devices. EDICI. Respir Med 2000;94(5):496-500.

13. Welch MJ, Nelson HS, Shapiro G, Bensch GW, Sokol WN, Smith JA, Parasuraman BM. Comparison of patient preference and ease of teaching inhaler technique for Pulmicort Turbuhaler versus pressurized metered-dose inhalers. J Aerosol Med 2004;17(2):129-139.

14. Wieshammer S, Dreyhaupt J. Dry powder inhalers: which factors determine the frequency of handling errors? Respiration 2008;75(1): $18-25$

15. Giraud V, Allaert FA, Roche N. Inhaler technique and asthma: feasability and acceptability of training by pharmacists. Respir Med 2011;105(12):1815-1822.

16. Voshaar T, Spinola M, Linnane P, Campanini A, Lock D, Lafratta A, et al. Comparing usability of NEXThaler ${ }^{\circledR}$ with other inhaled corticosteroid/long-acting $\beta 2$-agonist fixed combination dry powder inhalers in asthma patients. J Aerosol Med Pulm Drug Deliv 2014; 27(5):363-370.

17. Blasi F, Canonica GW, Centanni S, Mereu C, Bernabei R, Paolisso $\mathrm{G}$, et al. Genuair ${ }^{\circledR}$ usability test: results of a national public survey of the elderly. COPD 2016;13(3):367-371.

18. Ovchinikova L, Smith L, Bosnic-Anticevich S. Inhaler technique maintenance: gaining an understanding from the patient's perspective. J Asthma 2011;48(6):616-624. 


\section{Correcting Inhaler Technique in ExPerienced SubJects}

19. Basheti IA, Qunaibi EA, Hamadi SA, Reddel HK. Inhaler technique training and health-care professionals: effective long-term solution for a current problem. Respir Care 2014;59(11):17161725.

20. Chrystyn H, Dekhuijzen R, Rand C, Bosnic-Anticevich S, Roche N, Lavorini F, et al. Evaluation of inhaler technique mastery for budesonide formoterol Spiromax ${ }^{\circledR}$ compared with Symbicort Turbuhaler ${ }^{\circledR}$ in adult patients with asthma: primary results from the Easy Low Instruction Over Time (ELIOT) Study. Thorax 2015;70(Suppl 3): A154-A155.

21. Toumas-Shehata M, Price D, Basheti IA, Bosnic-Anticevich S. Exploring the role of quantitative feedback in inhaler technique education: a cluster-randomised, two-arm, parallel-group, repeated-measures study. NPJ Prim Care Respir Med 2014;24:14071.

This article is approved for Continuing Respiratory Care Education credit. For information and to obtain your CRCE

(free to AARC members) visit

www.rcjournal.com 